\title{
How cultural institutions prevent stigma around Lake Victoria
}
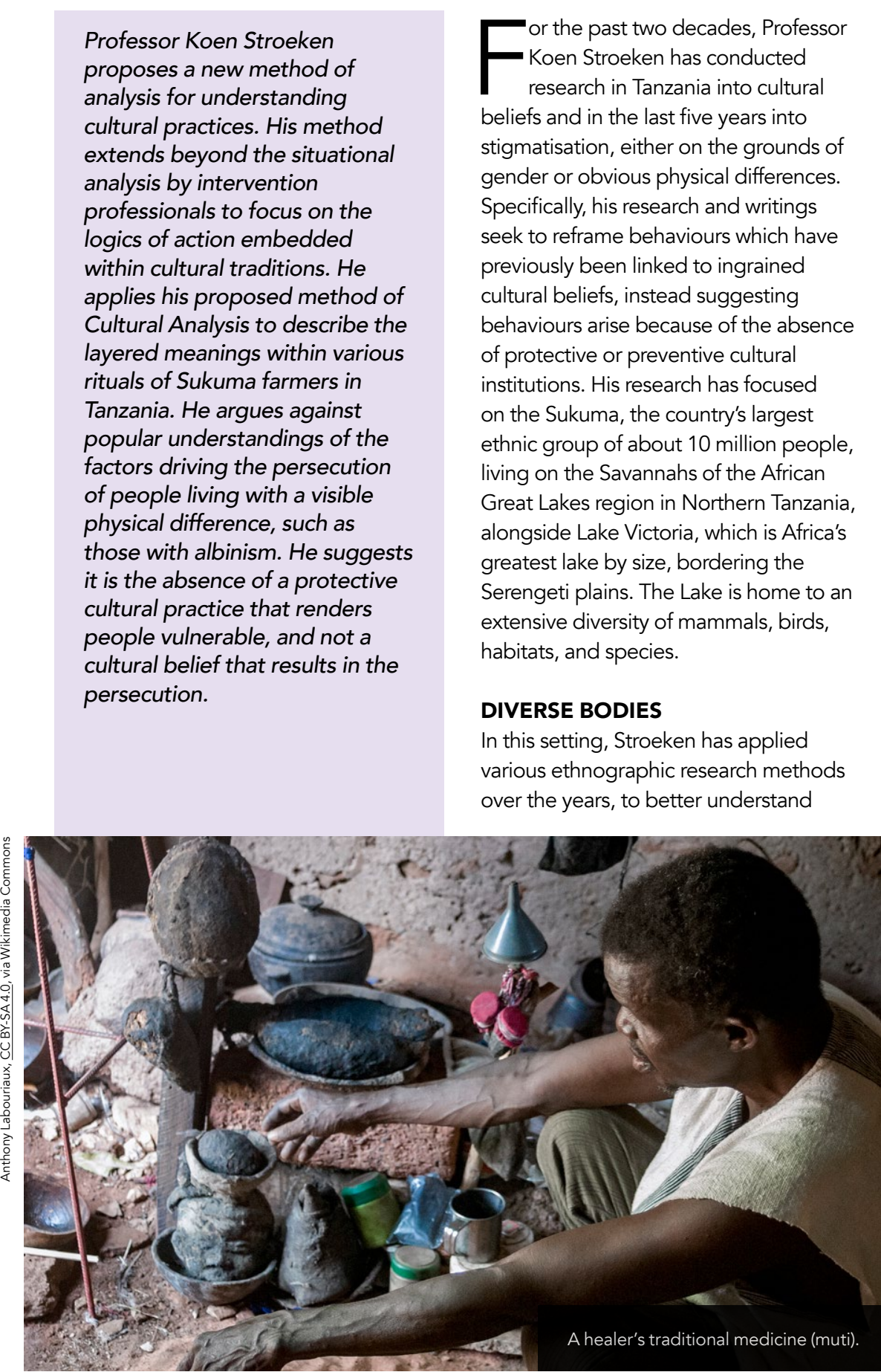

cultural institutions, especially rituals. His recent research focus has been on exploring how established rituals serve to transform the meaning of specific physica differences which set people apart and which might potentially place them at difference being interpreted as a threat to the group.

Professor Stroeken explains that culture is often incorrectly blamed for harmful practices within rural population groups. His research shows that it is the absence of cultural rituals that could be failing to protect people within communities who evidence divergent physical features. He argues that the blaming of culture arises due to incomplete analyses of what constitutes a cultural ritual, and the inability to differentiate these from harmfu practices locally categorised as witchcraft. As a result of this confusion, intervention practices may be ineffeverive harmful practices may be ineffective.

An example of this has been the focus on the killing of people living with albinism
in certain of the Sukuma communities. Albinism is a congenital disorder which results in an absence of pigmentation in the skin, hair, and eyes, and requires that people living with this condition protect themselves from the sun. People born with the condition often suffer stigmatisation on account of their differences, depending on where in the world they live.

Within some Sukuma speaking communities in Tanzania, a horrific new logic of action about the magical properties of the bodies of people living with albinism has resulted in the murder of these people. Professor
Koen's research indicates that the

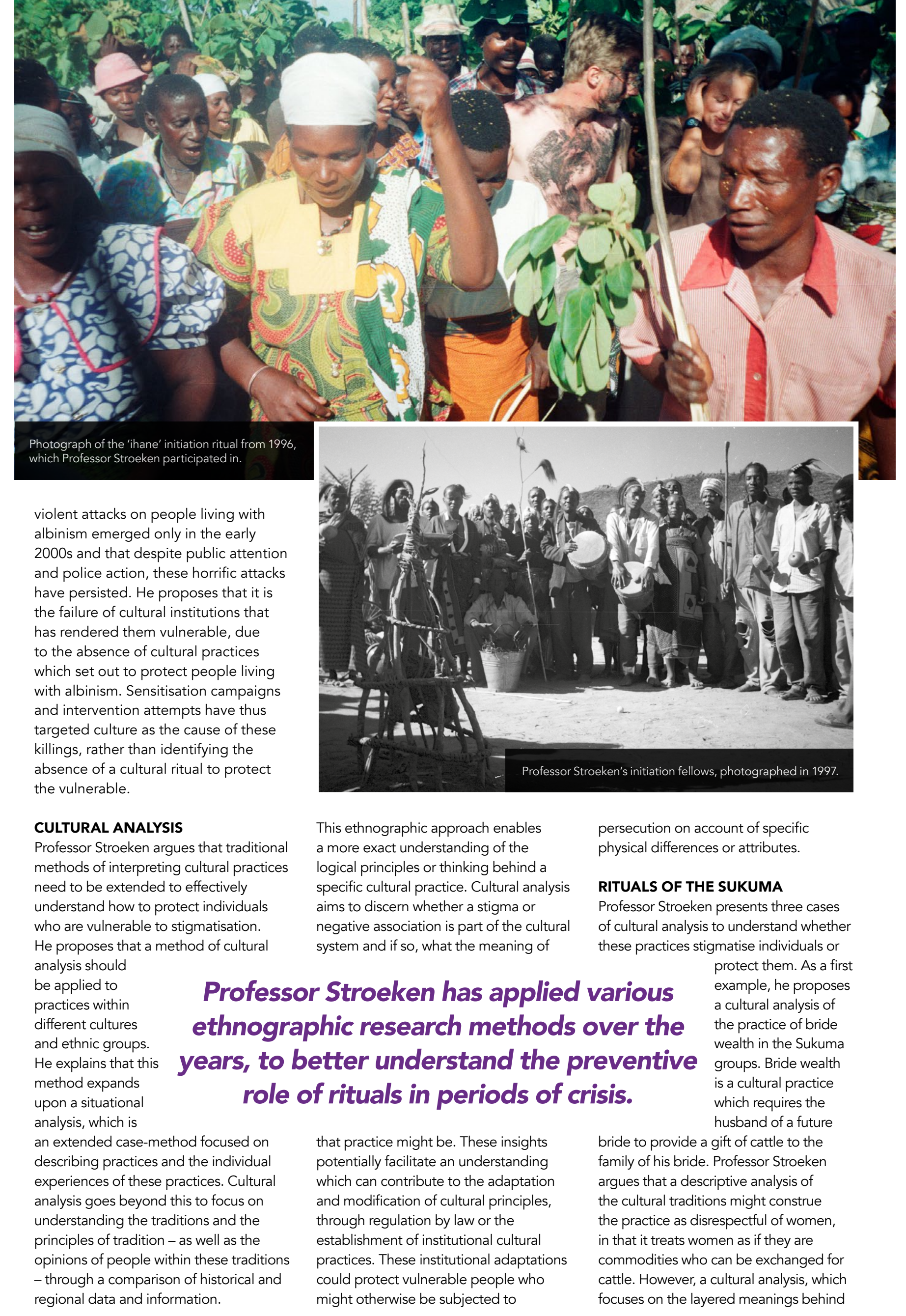


a practice, instead highlights a ritual symboling the reciprocity of exchange between facts the The gift exchange partnership for a network of subsequent gartership for a netwok of subsequent The bride wealth is an intermediate gift in that partnership.

As a second example of the value of cultural analysis, Professor Stroeken focuses on the 'nsebu': children whose birth circumstances are less common such as those born prematurely or conceived as twins. The Sukuma have elaborate purficication treatments involving these babies and their parents. These rituals adapt what migh therwise be perceived as a simple fear of difference leading to stigmatisation, and instead assign these babies special status, hereby transforming Stroeken says that babies classified as 'nsebu' - meaning heat (and implied danger) - undergo a series of rituals which transfer upon them a special status of 'mhola' (coolness), which implies fertility, peace, and good rains. The logic of these rituals thus enables otherwise vulnerable people to be protected against discriminatory beliefs and actions.

These rituals can therefore transform perceptions of causation in relation to difference, and can lead to the avoidance of stigma. Professor Stoeken says that this was also vident within newly invented rituals of sacrifice during the Hiv epidemic, protected women who survived the virus, even when their partners and children had died from the HIV virus.

\section{ITUALS OF PROTECTION} case of children living with albinism, there is in fact no cultural institution or itual treatment at all to protect them The vulnerabilities of living with this difference, which include not being able to work in the fields due to the risk of severe sunburn, are thus open to individual interpretation which can readily mutate into fear, stigmatisation, and perseculion. Professor Stroeken that these children leco stigmatised".

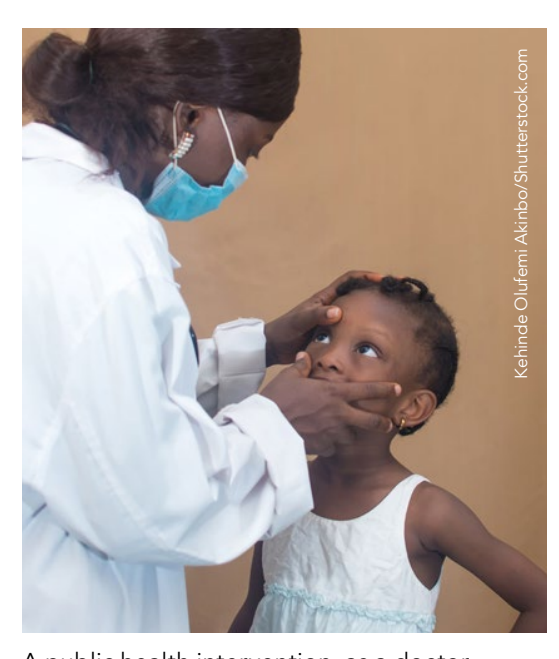

A public health intervention, as a doctor
carries out a medical check-up of a young child

A cultural analysis approach can help us understand which practices are harmful, which are designed to protect and prevent stigmatisation, and which circumstances leave groups of people vulnerable.

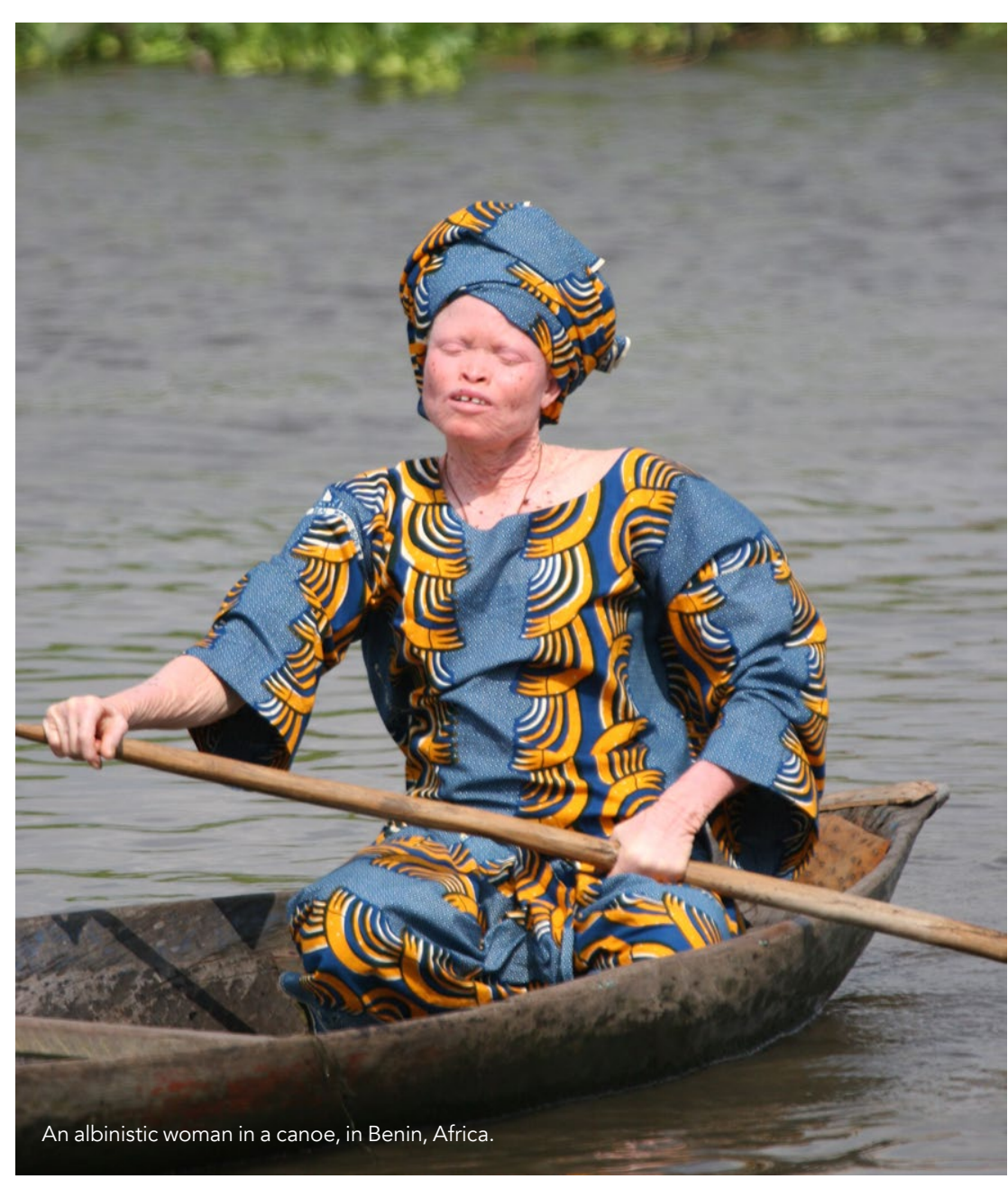

vinerable His ave groups of people

recognition that cultural institutions and

practices can transform the meaning

the prevalence of stigmatisation. He

argues that through this understanding,

interventions from outside the society

can focus on establishing protections
through cultural institutions and

practices, limiting harm to those who

are considered a threat to the group, on

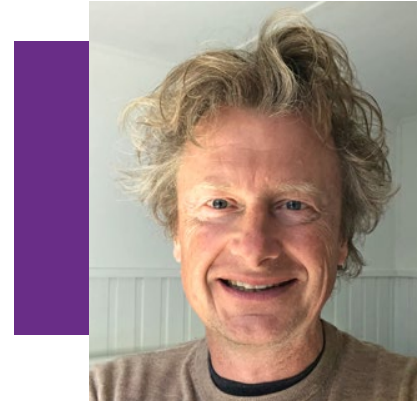

\section{Behind the Research}

Koen Stroeken

(2)

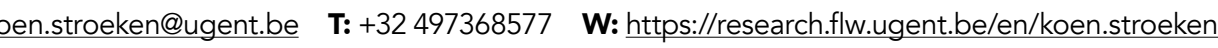

\section{Research Objectives}

Koen Stroeken's research largely deals with medico-political anthropology

\section{Detail}

\section{Address}

Blandijnberg 2

9000 Gent

Belgium

Bio

Koen Stroeken is an associate professor in Africanist anthropology at Ghent University. Based on ethnographic among others five peer-reviewed volumes, of which two monographs. Moral Power: The magic of wichcraft (2010) and Medicinal Rule: A historical anthropology of kingship in central and east Africa (2018). Stroeken co-founded CARAM, the Centre for Anthropological Research on Affect and Materiality, and coordinates since 2012 a VLIRUOS-IUS academic exchange with Mzumbe University (Tanzania). He was or is the supervisor of twelve PhD projects conducted in Africa, the Indian Ocean system and Latin-America.

Funding

- CARAM - Centre for Anthropological Research on Affect and Materiality (Ghent University)

https://research.flw.ugent.be/en/caram

-VLIR-UOS

https://wwwvliruos.be/en/projects/project/22?pid=4327 Collaborators

Paulo Magufuli, Sele Lukundula
References

Koen Stroeken (2020). Stigmatized Bodies Near Lake Victoria: A Cultural Analysis of Institutions. Foundations of Science, pp 1-11. https://doi.org/10.1007/s10699-020-09684-y

\section{Personal Response}

What would your recommendation be for a Public Health Intervention to prevent the killing of people with Albinism?

II The initiation called 'ihane' should be organised again, with a focus on contemporary issues. The killings
are based on beliefs in magic that fit the modern era of casino capitalism, yet the local traditions do not grant them legitimacy. Rituals of initiation teach about tradition the medicinal knowledge imparted on the participants, which the Church labelled as 'magic'. However, these plants and ancestral procedures are cultural mnemonics that prepare the initiated in times of crisis, to feel reassures people in need. The medicinal knowledge obtained during the week of initiation also offers a frame of reference about the wider cosmology and the ethical role of the ancestors so that the initiated will not easily be fooled by business-minded healers spreading thelief in powerful albinism-related body parts.
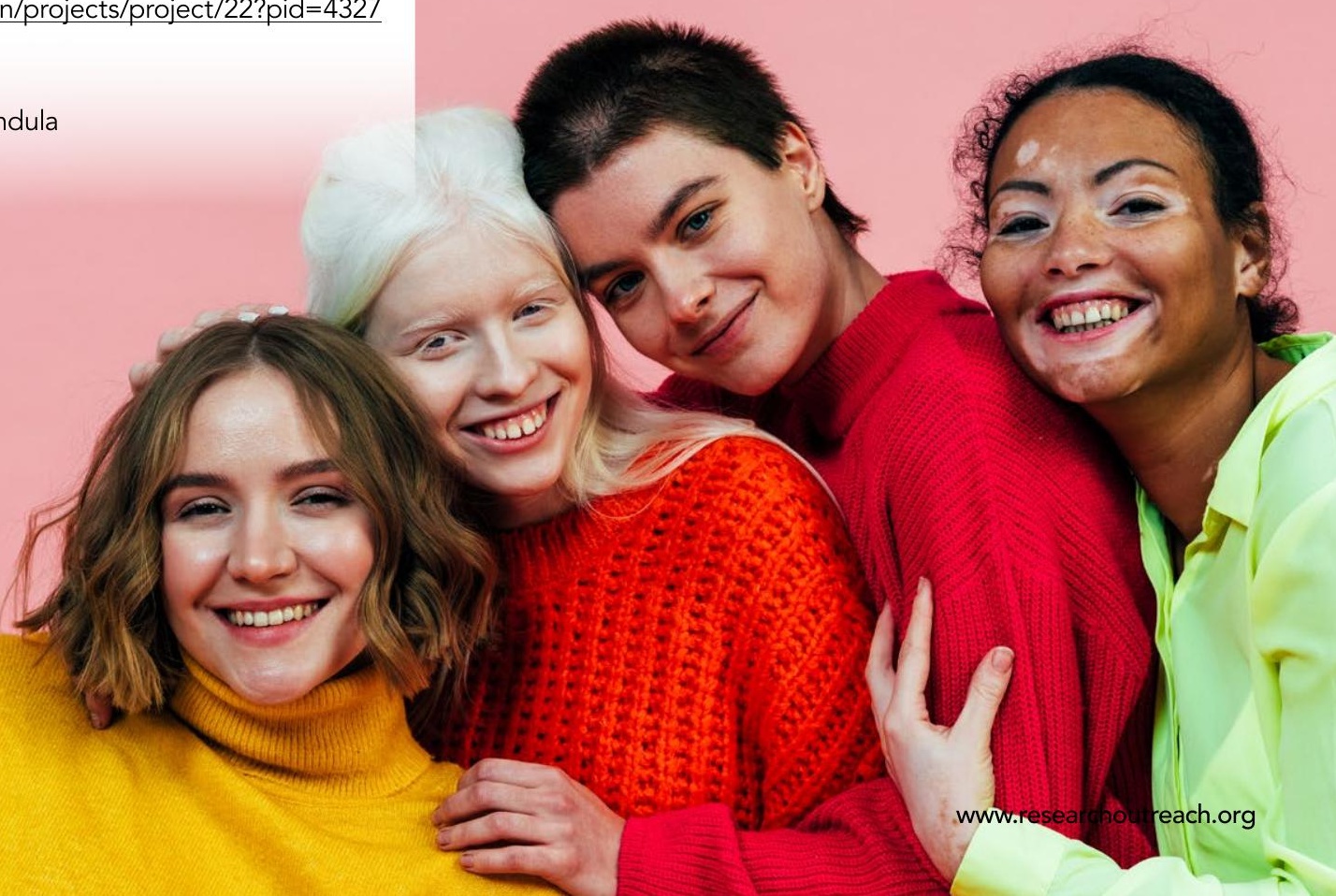